\title{
Leibniz' Weltanschauung als Ursprung seiner Gedankenwelt.
}

Zum 200. Todestage des Denkers am 14. November 1916.

Von H. Heimsoeth.

Seit den Jahren, da vereinzelt Forscher bei uns die grosse Aufgabe angriffen, den im Wesen halb verschollenen Ahnherrn des deutschen Idealismus - nicht lange vor der 200. Wiederkehr seines Geburtstages - einer unempfindlichen und vergesslichen Nation zuzuführen, ist viel schwere Arbeit getan worden, das Werk des Mannes allen zugänglich zu machen, es zu sichten und zu begreifen. Die Frage ist, ob er uus lebendig geworden ist seitdem.

Keine Seele rührte sich im zerfallenden Reich, als vor 200 Jahren der Geist zur Ruhe ging, der seinem Zeitalter doch, und weit über sein Vaterland hinaus, eine Macht vom höchsten Range bedeutet hatte, ein ganzes Menschenleben hindurch. Wenn heute auf diesen Tag zurückzublicken ist: wie gross ist jetzt die Gefolgschaft, wie breit die Wirkung? Wer, ausserhalb eines engen Bezirks von historischer wissenschaftlicher philosophischer Forschung, weiss von Leibniz; für wen lebt er? In dieser Zeit, da alles Deutsche sich zusammenschliessen und deutsche Vergangenheit lebendig machen möchte - wer spricht, mit erfülltem Sinn und erweckendem Herzschlag, von Leibniz? Wo ist Gegenwart, in der dies Stück deutschen Weltgefühls und Gedankens lebendig wirkte? Ist es nicht so, dass die Namen Spinozas, Shaftesburys, Descartes', Rousseaus mehr Klang und Gowicht haben in der Welt unserer Bildung und des gesamten geistigen Lebens als der des deutschen Ahnherrn? -

Immer das gleiche alte Verhängnis über dem deutschen Dasein; die eigenen Quellen und Gründe gehen dem nach aller Welt zersplitterten Bewusstsein verloren, die Fäden reissen wieder und 
wieder ab. Die grössten Zeiten unseres nationalen Geisteslebens in den Jahrhunderten vor Leibniz sind uns fremd, wie er es ist, der -- selbst schon einer Zeit angehörend, die den Zusammenhang mit der Vorwelt verlor - doch mit den Wurzeln von ihrem Gute zehrt, den mächtigsten Antrieb und reichsten Stoff aus ihr empfängt.

Wohl ist er selbst nicht ohne Schuld an der Fremdheit, die ihn nun von uns trennt: da ihm, dem geborenen Meister der deutschen Sprache, rasche und sichere Wirkung in die Breite der Gelehrtenrepublik aller Länder mehr galt, als die ungewiss mögliche auf deutsche Gegenwart und Nachwelt. Wagt man aber noch von Schuld zu reden, wenn man sich das Deutschland vor Augen stellt, auf das Leibniz wirken, auf dessen nationale geistige Zukunft er warten sollte? Und war nicht er es, der mühsam die ersten Mittel zusammensuchen musste zur Überbrückung der Kluft nach der deutschen Vergangenheit — zur Überbrückung wenigstens durch geschichtliches Forschen?

Wenn uns einmal doch wieder lebendig und Gegenwart werden sollte, was der deutsche Geist im 13., im 14. und 15. Jahrhundert empfand schuf suchte spekulierte - dann wird auch Leibniz, den die Nachwelt, nachdem "Aufklärung" seinen Tiefsinn zum Trivialen verkünstelt hatte, als den Philosophen der deutschen Aufklärung abstempelte, uns Lebendigeres und Gegenwärtigeres bedeuten können.

Aber bis dahin ist der Weg noch weit. Inzwischen bleibt die engere Aufgabe, ihn recht begreifen zu lernen, in seiner geschichtlichen Stellung und im Gehalt seines Denkens.

Die Frage liegt nahe, ob wohl von der Philosophie selbst der Zugang zu Leibniz' Gedankenbau auf die rechte Weise gesucht wurde. Damals, als man sich auf ihn besann, führte noch Spekulation das Wort. Das war guter Boden für den grössten spekulativen Kopf der deutschen Vergangenheit. Doch kam die Entdeckung zu spät, um noch entscheidend in der Neubildung mitzuwirken. Und die Historiker der Hegelschen und Herbartschen Schule gewannen nicht so viel eigenes Werkzeug, um eigene Wege zum wiedergefundenen Bau aufgraben zu können. - Dass aber die Zeit der alleinseligmachenden Erfahrungswissenschaft dem gigantischen Werk ratlos gegenüber stand, ist nicht verwunderlich.

- Eine Hochflut der Leibniz-Forschung kam mit der Verbindung vou Philosophie and Wissenschaft im Zeichen der Erkenntnistheorie 
herauf. Es entstanden die umfassenden Versuche, das System nach seinem wissenschaftslogischen Wahrheits- und Gegenwartswert zu durchleuchten. Sie konnten sich berufen auf enge sichere Zusammenhänge zwischen Leibniz' Spekulation und Leibniz' wissenschaftlicher Forschung und brachten Verwertbares genug an den Tag.

Aber ob sie den Kern der Sache treffen ist zu fragen. Sind Leibniz' vielspältige Begriffe nur Schnittpunkte wissenschaftlicher Problemlinien in logischer Verlängerung? Kann man die grossen Gedankenmassen, die darüber weit hinausreichen, als $\mathrm{Ge}_{\theta}$ dankenphantasie eines "rationalistischen Dogmatismus" wegstreichen, bei Seite lassen, ohne dass der eigentlichste Sinn des Ganzen verloren ginge? Hat dies System kein Herz, hinter allen Begriffen und Einzelproblemen, von dem diese ihr Leben empfangen, vor und trotz aller Sonderbedeutung? Gibt nicht ein persönlich überzeitliches Weltgefühl dem Ganzen den lebendigen Wert, dessen Wirkung nicht gebunden ist an Wissenschaft und Lehre - ein Welt- und Daseinsgefühl, das auch den Denker inniger mit deutscher Vorzeit verbindet, als in Forschung und Problemlösung sich finden lässt? Hat also nicht Leibniz, über alles gelehrte Interesse hinaus, in viel tieferem, viel allgemeinerem viel persönlicherem Sinne uns Wichtigstes zu sagen, über zwei Jahrhunderte deutscher Geistesentwicklung hinweg?

Dass es so sein möchte, dazu wollen die folgenden Zeilen Andeutungen geben.

In der Philosophiegeschichte ist es alte Übung, Leibniz' Systembegriffe auf Fragestellungen Descartes', als seines unmittelbaren Vorgängers - und weiter dann auf Gedankenbildungen und Lebensgefühl der italienischen Renaissance, als des Geburtsorts der ganzen neueren Philosophie, zurückzuleiten; - unter Beifügung etwa noch der Einflüsse von der religiösen Reformation in humanistischer Fassung und Vermittlung. Das so erhaltene Bild ist allerdings wenig geeignet, auf die wahren inneren Quellen jener abstrakten "Gedankenphantasien " der Monadenlehre hinzuleiten, noch den lebendigen Gehalt darin ins Licht zu setzen. In Wirklichkeit wird mit solcher Darstellung der geschichtlichen Beziehungen nur ein sehr beschränktes Stück aus der Bildungsgeschichte des jungen Leibniz, doch nimmermehr seine geistige Abkunft ergriffen. Das gilt nicht nur für sein Verhältnis zu Descartes, 
sondern, was von viel breiterer Bedeutung ist, für die Stellung im ganzen Zeitzusammenhang. Und es ist zu fragen, ob dieser selbst, auch von dem einen Denker abgesehen, bisher die rechte Fassung gefunden hat. -

Die Einsicht, dass die grosse Lebenswendung und geistige Wandlung, die den Anfang der europäischen Neuzeit bedeutet, nicht im 15. und 16. Jahrhundert sich vollzog, sondern im 13. und 14., und in ganz anderen Bewegungen, als man es seit Humanismus und Aufklärung glaubte, gewinnt zusehends Raum und dringt allenthalben in die Forschung ein; nur die philosophische Geschichtsschreibung hat davon noch kaum Notiz genommen. Und doch würde das Gesamtbild vom Werden der neueren Philosophie sich ändern müssen; und dies in einer Weise, die für die Einordnung und geschichtliche Wertung der deutschen Denker in den Zeiten bis auf Leibniz von unabsehbarer Bedeutung wäre.

Eine flüchtige Skizze zum neuen Bilde, im Hinblick nur auf unsere Leibnizfrage, sei gewagt. - In zwei grossen Strömungen kommt zuerst das neue Leben zum Sprechen und zur frühen Geistesblüte: Die eine führt von den englischen Inseln nach Nordfrankreich, die andere, nicht unabhängig von ihr, von der Provence nach Italien. Es ist die Erstere, die für die neuere und im Besonderen für unsere deutsche Philosophie von entscheidender Bedeutung wird. Mitten in der Hochscholastik und gleichzeitig mit deren gewaltigster Entfaltung setzt das neue Lebensbewusstsein sich durch, gestaltet sich Ziel und Begriff. Roger Bacon und, bedeutungsvoller noch, Duns Scotus und die um ihn - mit den Ausläufern Durand, Pierre d'Ailly, Gerson nach Frankreich übergreifend - machen den Anfang aus der zünftigen TheologiePhilosophie heraus.

Zugleich gewinnt die religiöse Gärung, die das Abendland erfüllt, deren Richtpunkt in der südlichen Entwicklung die einzige Gestalt des Franz von Assisi ist, im Norden, schritthaltend mit dem Aufwachsen der jungen Gotik und in deren engerem Ursprungsland, erste Gedankenform in der Mystik des Amaury de Bène und der Seinen; die breitet sich reissend aus und dringt, wie die einzige neue Kunst, nach Osten vor - über den Rhein.

Meister Eckehart wird der Vater der deutschen Philosophie, drei einhalb Jahrhunderte vor Leibniz. Die Kreise des Duns greifen in die seinen über. Von ihm an nimmt die unvergleichliche Bewegung der deutschen Mystik, aller Feindschaft zum Trotz, 
Leibniz' Weltanschauung als Ursprung seiner Gedankenwelt. 369

ihren Siegeslauf durch die. deutschen Herzen und bildet, mit den reichen Mitteln der selbstgeschaffenen heimischen Begriffssprache, den neuen Geist heran.

Der grosse Zug wird bald durchkreuzt. Jahrhunderte der Zersplitterung folgen. Fremde Einflüsse wollen das Eigene ergänzen, verbessern - und durchkreuzen nur, zerstören. Nikolaus von Kues macht den gewaltigen Versuch, das Überkommene und das Werdende, das Heimische und das von Italien her Erfahrene in ein universales Weltsystem zu spannen. Er bleibt vereinzelt und unbegriffen; nur im Süden findet sich ein später Schüler: Bruno, vou den man hat glauben wollen, dass seine ureigensten Erfindungen Leibniz' Welt erfüllten - weil doch die Ähnlichkeit in Einigem so schlagend war. Aber die Bildung geistiger Tradition ist auch in der Philosophie nicht gebunden an die Vormittlung durch die fertigen Gebilde, und ist es um so weniger, je tiefer der Gedanke im Erlebnis wurzelt.

Die Saat der frühen Mystik geht auch in Anderen auf; unter aller Zerstreuung und Zerstörung wirkt deutsches Wesen weiter. Aus der neu gewordenen Daseinsliebe zieht die deutsche Naturphilosophie und Theosophie die Kräfte zur Bildung eines Natursystems, das im Einklang ist mit der gewonnenen Fassung von Gottessein und Seele. Agrippa von Nettesheim und der grosse Paracelsus, mit ihnen Schwenckfeld, Weigel und Franck sind Höhepunkte einer breiten Entwicklung. Von ihrem und von Luthers Geist nährt sich die gewaltige einsame Kraft des Jakob Böhme, als des letzten grossen Meisters in der deutschen Philosophie vor Leibniz.

Wie nun dieser aufwächst, da ist die Verwirrung aufs Höchste gestiegen. Jede reine selbständige Kraft ist verschüttet, in der von allen Bildungselementen aus aller Herren Länder aller Zeiten hoffnungslos verstaubten deutschen Bildung ist keine Luft mehr für den Selbstdenker. Doch er wächst gewaltig hinaus über die erstickende Kleinwelt. Und er kehrt sich nicht einmal ab von dem Gewimmel der Meinungen, der künstlichen Traditionen und zusammengesuchten Stoffe; er unternimmt es, sie umzubilden, sie einzufügen in eine Struktur, anzuschliessen an einen Kern. Er traut sich, gegen alle Zeitgefahr des Eklektizismus, die Spannweite eines Weltgedankens $\mathrm{zu}$, der alles das noch mitumfassen kann, was er nicht selbst aus sich hervortreibt und in sich erlebt. Der Kern aber, die Gesinnung, die bildende Tendenz in ihm, der 
Tiefsinn und die Richtung seines Blicks, die eigenste Haltung zu Gott, Welt und Dasein - die sind vom Wesen des Böhme, des Paracelsus, des Nikolaus, des Eckehart. Wenn die Monadenlehre "Phantasie" ist, so sind es die Phantasien der deutschen Mystik and Naturphilosophie, sind es die Bilder des Kusaners und der Theosophen, die darin fortleben und neu werden; aus den gleichen Quellen strömt Gefühl und Sinn für diese wie für jene. Stoffe sind es, Einzelprobleme und -aufgaben, Begriffshilfen, Anknüpfung und Ausdruck, was Leibniz den Zahllosen entnimmt die er zitiert, and an die man darum anknüpft, wenn man von ihm spricht. Die innerlichst wirkende Tradition des Geistes aber war noch meist verschwiegen.

Leibniz' System erwächst, nicht anders als die Gedankenbildungen aller seiner deutschen Vorgänger, auf dem Boden einer religiösen Lebensstellung. Die überall durchdringende Zeitströmung, die von Renaissance und Humanismus her auf vollkommne Abtrennung der Philosophie von allem Religiösen hinarbeitet, findet in ihm den unbedingtesten Gegner. Doch ist es nicht anpassende Kombination von kirchlicher Glaubenslehre und überlieferter Weltweisheit, nach der Art noch der protestantischen Zeitphilosophie, die ihm genügen könnte. Die Erkenntnis des Göttlichen und Ewigen muss selbst zu den Grundlagen des Weltbegriffs und bis in seine Ausläufer hinein führen. So erstrebt es die heimische Tradition seit Eckehart; in dem einzigartigen Stück aus Leibniz' deutschen Schriften „Von der wahren Theologia mystica“ is innere Verwandschaft mit Händen zu greifen. Es gibt ein gar falsches Bild, wenn man, wie in soviel anderen Fragen den Eigenkern der Leibnizischen Welt vergessend über allerlei synkretistischen Zügen, die alles bedingende Ursprnngsverbindung von religiösem und metaphysischem Erleben zu einer der "Versöhnungs-“ Absichten des weitherzigen Mannes verflacht. -

Wenn Leibniz immerfort "Gott und die Seele“ als das letzte und eigentliche Thema des Philosophierens anführt, auch da wo auf Körper Materie Natur die Forschung geht, so hat das eine nicht nur ernsthafter gemeinte, sondern vor allem sachlich durchgreifendere Bedeutung, als für die Metaphysik des Descartes die Titelbegriffe seiner "Meditationen". Der Tendenzgedanke der Confessio Naturae durchzieht das ganze Lebenswerk; er ist es, der den Philosophen mit dem Wissenschaftler sich verbünden, ihn 
auf so weite Strecken in die Naturerforschung sich vertiefen lässt: Kampf gegen Atheismus und Naturalismus, den „blossen Physikern“ zum Trotz, doch gerade mit Beweiswaffen aus ihrem eigenen System. Die Kenntnis der „Naturgebräuche“ an und für sich wäre ihm, darüber lässt Leibniz keinen Zweifel, soviel Hingabe nicht wert gewesen.

Die unablässige Fehde gegen die "Neuerer", gegen die alles überflutende Wirkung der Schriften der Hobbes Gassendi Descartes und ihrer Gefolgschaft bedingt immerfort Anknüpfung an Begriffe und Gesetze der Naturwissenschaft. Was man so oft vom Gelegenheitsakzent der Darstellungen aus Leibniz' Hand gesagt hat, gilt hier vor Allem. Der sachliche Ausgang des Systems liegt nicht in den Begriffen von Ausdehnung und Bewegung, sondern wirklich in denen von "Gott und Seele" und es heisst die innere Ordnung der Gedanken auf den Kopf stellen; will man diese zum Beiwerk von Anpassung und barocker Dekoration, und dafür die Bearbeitung des mechanischen Naturbegriffs zum Kern des Ganzen machen. Wie könnten auch die Begriffe der Metaphysik ursprünglich zu gewinnen sein aus einer Sphäre, die unbedingt nur zum bloss Phänomenalen gerechnet werden soll? Nicht als hypothetische Erklärung gegebener Erscheinungen, sondern als demonstrativer Bau auf dem Fundament einer spekulativ-apriorischen Ontologie will das Begriffsystem von Leibniz gelten.

Es sind die Gedanken zu jener reinen Seinslehre, in denen, des intuitiven Charakters entkleidet und in logische Gestalt gebracht, die Bildungsformen von Leibniz' Weltanschauung stecken; und in dieser Fassung beherrschen sie das ganze System. Immer ist es doch so, dass der philosophische Genius die persönlichsten Züge seines Weltbildes als das Selbstverständliche an sich der Diskussion vorausnimmt, und es ist die besondere Art spekulativer Denker, solche Vorwegnahme in Prinzipien mit dem Anspruch apriorischer Allgemeingeltung zu formulieren. Nun ist diese Erste Philosophie für Leibniz dem Hauptteile nach nichts anderes als „natürliche Theologie". Sie spricht von Gott nicht als dem Inhalt des Glaubens, sondern als dem in Wesenssätzen aufzuweisenden, und für den wahren Welt- und Daseinsbegriff unentbehrlichen Grund der Existenz und ihres Sinnes.

Dabei ist nicht die rationalistische Fassung das Charakteristische; darin steht Leibniz auf dem gleichen Grund etwa mit Thomas von Aquino. Die Vereinigung von religiöser Gewissheit und philoso- 
phischer Forschung erfolgt aber jetzt nicht durch Vermittlung eines Stufenprinzips, das Jedem sein eigen Bereich zuteilte; hier wird wirkliche ursprunghafte Erkenntniseinheit angestrebt, wie das bei Eckehart geschah; durch keine Offenbarung und Tradition beengte (wenn auch etwa dadurch nach der Glaubensrichtung hin ergänzte) religiöse Spekulation. Ob diese mit dem Organe mystischer Intuition oder mit der diskursiven Vernunft arbeitet, ist erst spätere Frage. Das Wesentliche liegt in der Absicht, die grossen religiösen Grundfragen des Seins, die der Offenbarung und dem Dogma allein überantwortet waren, intelligibel zu machen, sie in einem reinen System von Ideen zu erfassen. Selbständige Wesensforschung auch im religiösen Gebiet gegen Abhängigkeit von der theologischen Tatsache, das bedeutete das Ringen von Eckehart, von Nikolaus und allen den anderen. Der „religiöse Universalismus" ist die nächste Folge, "natürliche Theologie" wird allen unmittelbar zugänglich, die zum Erkennen letzter Dinge Willen und Fassungskraft haben.

Unmöglich, dass diesem Wesensbegriff ein Widerspruch entstehen könnte aus Tatsachen und Eindrücken der Offenbarung. Hart stellt die neue Zeit ihr Selbstvertrauen und Unmittelbarkeitsgefühl überlieferter Abhängigkeit und betonter Spaltung entgegen. Nicht als ein neuer Lösungsversuch für das alte Kirchenproblem ist diese „Versöhnung von Glauben und Wissen“ zuerst zu verstehen, sondern als die programmatische Prägung eines umfassenden Daseinsgefühles. Nicht dass er rationalistischer Theologe, sondern dass er religiöser Denker war, bestimmt wurzelhaft die Struktur von Leibniz' Gedankenwelt. Der durch die Entdeckungen und Wertungen christlicher Religiosität vertiefte Blick will alle Züge von Welt und Leben in neuer Totalität zusammenschliessen. Leibniz' Philosophie ist religiöser Idealismus. Nicht die Tatsache und das Sein behalten das letzte Wort, sondern der Sinngehalt und die vollkommene Person. Im christlichen Gottesgedanken wird der persönliche Träger des objektiven Geistes gefasst. Alles Sein und Dasein ein Sinngefüge, im letzten Grund und Ursprung zur Person krystallisiert; der Wesensgehalt alles Wirklichen und Möglichen gegeben in den Ideen in Gottes "Verstande“, und die Auslese des Einen Wirklichen aus dem vielfach Möglichen, der Gehalt des Daseins bestimmt durch allesumfassenden immanenten Wertvorzug, zusammengezogen in den einen "Willen" Gottes - der eben darum nicht "Willkür" sein kann. Und eben diese 
Scheidung zu den ersten Wahrheiten der Seinslehre gehörig: gälte sie nicht, so verschlänge (wie bei Spinoza) das Sein den Wert und das persönliche Leben. Das Letztbestimmende des Daseins ist aber nicht Sein als solches, sondern Geistesstruktur, Inbegriff alles Wesens und Wertes. Das, was ein Ding ist, und das, warum, wozu es ist, das allein ist Bestand an ihm, Idee, und liegt verankert im ewigen Geist; die Tatsache an und für sich kommt nicht einmal in Frage, ist nichts. Das Sein geht auf im Sinn; Träger und Quelle alles Sinnes aber ist zuletzt Person. -

Schon von hier aus ist entschieden über die Bedeutung von Raum und Zeit für die metaphysisch wahre Welt. Mit der Tatsache werden auch sie zum Belanglosen gerechnet, das nicht zur innersten Realität gehören kann. Im Sinngefüge gibt es wohl Beisammen, aber nicht isolierendes Gegeneinander, ausschliessende Undurchdringlichkeit, äussere Wirkung; in der Ideenwelt gilt nicht Veränderung, schiesst jede Ereigniskette zum zeitlosen Akt zusammen. Der Geist ist überall zugleich und obne Zeit. So klang es bei Eckehart und bei Nikolaus durch; so wird es Ursprungsforderung für Leibniz - zu der er dann die begriffliche Fassung und die Vereinigung mit allen sonst gegebenen Ansprüchen erst finden musste. Notwendig und gewiss im Ursprung, aber zweischneidig und vielfach durchkreuzt stellt der Gedanke sich ihm in der Durchführung dar; vor allem will sich die Phänomenalität des Zeitlichen nicht vereinen lassen mit der fundamentalen Daseinsaufgabe der Seele und aller Kreatur. In der Mystik und bei Cusanus war dieselbe Kluft, und war nur scheinbar überdeckt; Leibniz' strenge Begrifflichkeit zeigt unvermittelt die Gegensätze mit einander. Es ist noch völlig ungeklärt bis heute, wie Leibniz den Phänomenalitätsbegriff verstand und durchzuführen dachte; klar und gewiss aber ist der religiös-idealistische Ursprung der darin beschlossenen Gedankengänge. -

In der personal-geistigen Fassung des Seinsgrundes begreift Leibniz aber zugleich doch dessen Unterschied vom Dasein, grundsätzliche Dualität von Gott und Universum. Wie Keiner in der Reihe vor ihm ist Leibniz sich der Gefahr des Pantheismus im neuen Welterlebnis bewusst. Darum vor allem besteht er, gegenüber allem Plotinismus in der deutschen Tradition - die auch inm selbst wohl nocb im Blute steckt - auf dem theologischen Schöpfungsbegriff. 
Doch ringt mit der Ueberzengung jener letzten Dualität und bleibenden Geschiedenheit die andere um Versöhnung - eben jene, die alle dem Pantheismus in die Arme treiben wollte: das beseligende Erlebnis der neuen Zeit von der Herrlichkeit des Daseins, der Majestät der gotterfüllten Natur, der Immanenz des Göttlichen in Seele und Dingen. Abkehr vom Diesseits, Misstrauen in Erdenwelt Natur Körper und Sinne - zum philosophischen System gefasst durch platonisierend dualistische Steigerung des aristotelischen Gegensatzes von intelligibler Form und sinnlichem Stoff - löst sich nun auf in religiös bestimmter höchster Daseinsliebe. Die schroffe Zweiheit, Weltpessimismus und Erlösungsglück, Bewusstsein des Lebens in der Unvollkommenheit und gottinniges Vertrauen, mit Spaltung und Feindschaft noch bei Eckehart, Cusanus, Böhme nachklingend in so Vielem, wird sun durch Leibniz aufgehoben in eine gewaltige, Zeit und Ewigkeit umfassende Daseinsbejahung, in den unbedingtesten vollkommensten Optimismus, der je philosophische Fassung gefunden hat. -

Nach der alten Unterscheidung von affirmativer und negierender Theologie ist Leibniz zur ersteren Art za rechnen, die ja stets mit dem Schöpfungsgedanken verbunden ist. Gott ist ihm, der auflösenden Tendenz neuplatonischer Tradition entgegen, der „bedeutungsreichste Begriff“. Die Vollkommenheitsattribute Gottes nun sind ihm zugleich die Wesensgehalte der ihm gegenüberstehenden Wirklichkeit (entsprechend die primären Wesensinhalte des Erkennens). Der Sinn, der Logos vermittelt auch hier zwischen Gott und Welt, deren Dasein darum doch getrennt bleibt. „Gott ist von der Natur frei, und die Natur ist doch seines Wesens" sagt Jakob Böhme.

Und da gibt es nichts Widerstrebendes und Fremdes ausser den Gottesattributen - nur deren Einschränkung; kein Stoff, den gottgeborene Form nur teilweise bewältigte, nicht Rückstand toter passiver schlechter Materie. Ausser Gott ist Nichts; von diesen beiden Faktoren der Schöpfung kommt dem zweiten auf keinem Umweg Positivität zu. Nicht nur das formhafte Beste entspringt und entspricht Gottes Wesen und Sinn, sondern Alles schlechthin; Unsinn und Unwesen im eigentlichen Verstande gibt es nicht. Die Welt, ob sie gleich Gott gegenübersteht, nicht selbst Gott ist, ist doch nach Wesen und Wert einheitlich durch und durch: Einheit die sich nicht spalten lässt in Geist und Materie, Intelligibles und Sinnliches, Gottähnliches und Gemeines. Vollkommene Gottes- 
transzendenz im Dasein geht zusammen mit vollkommener Gottesimmanenz im Wesen. Wenn der begriffliche Unterschied von Form und Stoff bestehen bleibt, so wird diesmal die Daseinsfreudigkeit des Aristoteles betont, für welche die Ideen nicht jenseitiges Ziel der Sehnsucht, sondern allen Dingen ursprunghaft innewirkende Kräfte bedeuten. Stoff ist nichts als das Moment der Endlichkeit, der natürlichen und selbstverständlich hinzunehmenden Begreuztheit jedes Existierenden; weder ein Feindliches also, noch überhaupt, wenn man nicht unbillig diese Seite des Daseins isoliert, etwas das niederzieht, hemmt, zu beklagen wäre. Die Begrenzung ist zugleich der positive Sinngehalt des Einzelnen, das Aussondernde, in dem es sich individualisiert und seine einzigartige Aufgabe und Bedentung übernimmt. Mannigfaltigkeit ist nicht weniger "intelligibles" Sein als Einheit; und das "Sinnliche" bildet kein Sonderreich neben diesem. So sind denn auch Körper und Seele nicht fremde und auseinanderstrebende Prinzipien, nicht zwei Seinsformen, zwei Substanzen gar (wie der Cartesianismus wollte, der darin so wenig vom neuen Lebensgefühl zeigte), sondern die beiden nach Sache und Sinn untrennbaren Aspekte kreatürlichen Lebens; in ihrer Einheit beide zu bejahen, wie geschaffenes und also eingeschränktes Dasein überhaupt Bejahung fordert.

Es hat nicht nur jede Existenz ihr zeitloses Wesen, ihre Idee, sondern es hat auch jede ihren unvergleichlichen und nicht zu ersetzenden Wertsinn, den höchsten der nur dafür gewünscht werden könnte. Dasein definiert sich als das eine System maximaler Vollkommenheit aus dem Stoffe der unbegrenzten „Möglichkeiten “, die in den Ideen gegeben sind. Schöpfung bedeutet die Realisierung der mit "unfehlbarer" Sicherheit in der Logoswelt vorgezeichneten Auswahl des einen besten, höchstwertigen Systems; determiniert nicht durch Notwendigkeit des Wesens, deren Verfehlen ontischer Widerspruch wäre, sondern durch die Sinnstringenz des Wertes, mit dem Widerspiel der „moralischen Absurdität.. - Nie wurzelte abstrakteste Begriffsbildung tiefer im letzten Daseinserlebnis religiösen Allvertrauens.

Hier ist der Ort des vielberühmten Satzes vom zureichenden Grunde, in dem man den Gesamtausdruck von Leibniz' aufklärerischem Rationalismus zu sehen gewohnt ist. Seiner Bedeutungen sind viele; das ontolo'gische Prinzip vom Grunde hat zwei Hauptformen: das Sein ist restlos durchdrungen von Ratio - und: der 
„zureichende Grund“ für alles Dasein ist das Prinzip des Besten. Nun ist zwar oft betont worden, dass "Vernunft" in der Geschichte des Denkens nicht immer und nicht zuerst das eigentlich rationalistische Prinzip bedeute; doch denkt man, scheint es, weniger daran, dass solches für die Ratio nicht minder gilt. Dass alle apriorische Struktur, alle Wesensstringenz eine diskursivlogische Kehrseite hat, berechtigt nicht dazu, diese als deren Kern anzusehen. Und wenn schon der Logiker Leibniz wohl dahin zielte, so muss doch darum nicht das innere Bildungsgesetz seines metaphysischen Systems, nicht der Kern seines Weltgedankens in dieses Schema passen.

Versteht man nun also Ratio in Leibniz' Prinzip nicht als den logischen Grund (was auch dem Satze die restlose Durchführbarkeit rauben müsste), sondern als den "Sinn“, so kommt man wiederum zurück auf jene $Z$ weiheit von Wesen und Wert, wie sie hier in letzter Einheit gefasst werden soll: alles Sein ist bis ins Letzte sinndurchdrungen, von der Idee bestimmt und - Dasein bedeutet letzte Sinnsteigerung, höchste Wertverwirklichung, von unendlichen Kombinationsmöglichkeiten zeitloser Wesen sich abhebend. Der Optimismus erscheint als Steigerung des Idealismus. "Vollkommenheit ist nichts anderes als Quantität der Wesenheit"; und so tendiert jede Essenz aus sich zur Existenz, der "Konflikt" der Essenzen löst sich im vollkommensten System. Der Satz vom Grunde, das Prinzip des Wesenszusammenhanges ist zuletzt Prinzip immanenter Teleologie und als solches das allbeherrschende Daseinsgesetz, - Leibniz' Determinismus im Gegensatz zu jedem seinslogischen (Spinoza) oder kausalen Determinismus ein teleologischer - von dem dann eine Sonderwendung sich als göttliches Vorherwissen und Vorausbestimmtsein gibt für alles was je ist und geschehen wird. Immanente Teleologie ist das erste und für Alles einzig entscheidende Daseinsgesetz. In dem System des Besten hat jedes Dasein seine sinnbestimmte Stelle; und an dieser Stelle ist es eben so gut und so vollkommen, als da nur eines sein könnte; jeder Wunsch nach Anderssein beruht auf einem Zuwenig an Einblick, verkennt den Zusammenhang. Je tiefer man eindringt in das Ganze, um so sicherer wird man alles Dasein konform dem höchsten Anspruch finden. - Nicht Rationalismus also, sondern höchstgesteigerte Sinngläubigkeit bezeichnet den tiefsten Grund von Leibniz' Weltbaltung! Nur wenn man das Prinzip so versteht, begreift sich 
auch die vielfache Anwendung und Ableitungskraft, die für Leibniz in ihm gelegen ist.

Das alles folgt für Leibniz schon ohne weiteres aus dem Begriffe Gottes, ist ihm enthalten in der wahren Gottesliebe. Wie wäre die möglich für den, der die Dinge da und dort anders, besser wünschen und, wenn er könnte, anders machen würde! Ist Gott der Schöpfer der Welt, so muss diese auch die Spuren Gottes allenthalben und ohne Rückstand zeigen. So auch im Menschen: kein Zwiespalt bleibt da, nichts Abzuwerfendes. Sinnlichkeit und Instinktleben haben ihren vollen Sinn an ihrer Stelle: Körper gehört zur Seele in jedem endlichen Wesen und für alle Ewigkeit. Diesseits und Jenseits, Leben vor und Leben nach dem Tode schliessen sich in eine homogene Reihe zusammen; der Begriff des Universums, das keinen Anfang und kein Ende in der Zeit hat, fasst beides in sich. Flucht von der Natur, vom Leibe, von den Affekten würde mangelndes Gottvertrauen zeigen hier (als beim Gegenpol der Lehre Schopenhauers) ist es. der Pessimismus der, auch in der eingeschränktesten Form, als „ruchlos" gilt! Schon der Gedanke, dass im Dasein etwas indifferent stehen könnte zum Wert, ja der, dass etwas bloss als Mittel am Wert teilhaben könnte, wird schroff abgewehrt: darin vor allem schon erweist sich die mechanische Naturansicht der "Neueren" als metaphysisches Unding. Die „Endursachen" bestimmen alles was ist und wird, nicht blind wirkende Kräfte. Und es gibt keine blosse Masse, kein blosses Geschehen der „Bewegung"; alles was ist, ist „vernünftig“, ist Ausdruck des objektiven Geistes, der überall und bis ins Letzte Kleinste Vollendung zeigt.

Damit ist Leibniz' Lebensproblem der Theodizee gegeben, die unvermeidlichste Aufgabe für jede religiöse Stimmung, die aus umfassender Liebe - pantheistisch oder nicht - zu Dasein und Natur uneingeschränkt ja sagen will. Stoa und Neuplatonisnuus in religiöser Spätantike, Eckehart, Cusanus, Böhme, der ältere Helmont im Werdegang des neuen Geistes zeichnen die Möglichkeiten vor, auf denen Leibniz' aus ästhetischem Erlebnis gewonnener Lösungsbegriff der "Harmonie“ beruht: nach welchem kein Missklang von Sünde und Übel, den man in isolierter Einzelheit wohl genug erlebt, dem rechten Ganzen eingefügt und in ihm verstanden, als das bestehen bleibt, wie er sich gab; vielmehr zur Steigerung und zur Vollendung höchsten Einklangs wird und als das „Passende“ dann selbst den Schimmer der Vollkommenheit 
empfängt. Die Versöhnung der Gegensätze, die die Mystik in Gott erschaute, überträgt so sich auf die Welt.

Die Ratio sufficiens, das Harmonieprinzip ist Gott; so trägt alles Wirkliche die Spur Gottes. So erhält die geschaffene Welt, sonst in schroffem Gegensatz gedacht zu der überlegenen Ordnung des Göttlichen, den höchsten Wert, der ihr sinngemäss zukommen kann. Jeder Beiklang des Bedauerns, jedes "Nur" gegenüber ihrer Begrenztheit wäre verfehlt, Gott und Welt, beide werden rückhaltlos und jedes für sich geliebt, bejaht; doch ist es die Welt, die ihren Wert vom Göttlichen erhält, von ihm zu einer eigenen Form und Funktion entnimmt.

Ihr Sinn und ihre Aufgabe ist die Spiegelung Gottes; das ist, nach des Cusaners Vorgang, die Leibnizische Form des Immanenzgedankens. Das ganze Wesen Gottes krystallisiert sich in dem Akt der Schöpfung, in der Identität von höchstem Sinn und Wirklichkeit. So zieht denn auch das Universum die aktuelle Unendlichkeit in sich, die der christliche Gottesgedanke, allem Vollkommenheitsempfinden in der Philosophie des klassischen Altertums zuwider, als erstes Merkmal mit sich führte. Die Übertragung ist nicht neu; mit Duns und dann in gesteigerter Kraft mit Eckehart beginnt sie, und ihr neues Seinsgefühl wirkt in Nikolaus, dann in Bruno den Weltbegriff der neuen Zeit; seine Vollendung, die äusserste Steigerung bringt Leibniz, in dessen frühesten Schriften schon der Gedanke in aller Reife, wenn auch nicht mit den späteren Durchführungsmitteln, auftaucht. Tiefer als bei jenen allen dringt hier das Unendlichkeitsgefühl in die antike Weltordnung ein und wandelt sie um. Was immer wirklich sein mag, und sei es das Geringste, es trägt Unendlichkeit in sich, nicht nur in aristotelischer Möglichkeit, sondern gegenwärtig, notwendig, sinngemäss. Zeigt sich vorgebliches Sein als endlich fassbar, auszuschöpfen, so ist schon damit seine Irrealität bewiesen. Nur das Inkommensurable ist wirklich. Vollendete Unendlichkeit eignet der endlichen Kreatur; darin hält sie die Möglichkeit, Gott zu spiegeln. Unendliches und Endliches stehen im gleichen Gesetz, im gleichen Grundwesen; das Unendliche ist das Zunächstgegebene, das Vertraute, das Rational-sinnverständliche, nicht das Endliche, das, wo es als selbstgenugsame Abgeschlossenheit, schlechthin Begrenztes, sich behaupten will, vielmehr als „blosser Schein" leicht zu entlarven ist. Nicht das Unendliche eine Fortsetzung und Steigerung des Endlichen, sondern das End- 
liche eine spezielle Form und Spiegelung des Unendlichen: damit dringt die Kraft ursprünglichster religiöser Daseinsliebe vor bis zu den Sonderfragen der Wissenschaft - auf deren Boden dann neue Begriffsmittel und glückliche Bestätigungen für den grossen Gedanken sich finden.

Vom Gottesgedanken her ist so der Grundriss des Weltgebäudes vorgezeichnet, der allgemeine Stoff bestimmt. Es ist dann der andere Zielbegriff - die Seele - der zum inneren Aufbau weiterführt, die erfüllende Struktur des Ganzen bedingt. Seit jenem radikalen Wechsel der Blickrichtung, den das Christentum, begleitet von Strömungen der späten Antike, heraufführte: alles geistige Interesse schliesslich vom Kosmos abziehend und der reinen Innerlichkeit mit der in ihr sich aufbauenden Welt zuwendend - war der Boden bereitet für den Gedanken, der dann in der neueren Philosophie eine so einzige Bedeutung ge-. wonnen hat: Dass in der Selbstschau des Ich, im reflexiven Selbsterleben der Person die innigste Berührung mit der Gottheit nicht nur, sondern damit auch die einzig unmittelbare und sichere Grundlage für die wahre Erkenntnis der Umwelt zu erlangen sei. Augustin und vor allem Scotus Erigena legen den Keim dem dann mit der Versöhnung von Seele und Welt, Vollkommenheit und Kreatur, wie sie von der beginnenden Neuzeit erstrebt und geglaubt wird, mit einem Male von überall die reichste Nahrung zufliesst. Durch das Icherleben zur neuen Seinserkenntnis durchdringen, die wahrhafte Welt zur gegebenen Seele suchen nicht wie im Altertum Mensch und Subjekt zum gegebenen Kosmos: das ist treiben res Motiv in jenen Entwicklungszügen von Pierre d'Ailly und Raymond de Sabonde über Montaigne zu Descartes, von Petrarca zu Campanella, von Eckehart durch den breiten Strom der deutschen Mystik und Theosophie, über Nikolaus von Kues, Valentin Weigel, Paracelsus, zu Leibniz. Nirgends aber wird der Gedanke, als ein tiefstes Zeichen der Verschmelzung germanischen Wesens und christlicher Empfindung, so gross erlebt als in der deutschen Reihe; und keiner von allen Denkern zieht so die Konsequenz wie der Schöpfer der Monadenlehre.

Von hier aus, nicht durch bloss formal-ontologische oder gar wissenschafts-theoretische Erwägungen, wird Leibniz' Reform des Substanzbegriffs letztlich bestimmt. Die Welt der Scholastik, mit 
den Mitteln der Antike ausgebaut, wurde die alte Überwertung des Allgemeinen nicht los - die doch so schlecht zu dem Kern der religiösen Lehre passte. In ihrem Dualismus fiel, was das Einzelne zum Einzelnen und Einzigen macht, auf die negative materielle Seite; als wenn nicht gerade im innersten Quell des christlichen Erlebnisses die Überzengung vom unvergleichlich höchsten Daseinsgewicht der einzelnen Seele, der Person wurzelte! Das Erbe Plotins so gut wie das des Aristoteles brachte Zweideutigkeit und Versagen in dieser Frage mit sich. Je eindeutiger aber mit der Zeit jenes christliche Prinzip der individuellen Seele zum eigentlichen Grundwert des europäischen Kulturkreises sich herausbildete, um so dringlicher musste die Forderung nach philosophischer Neuordnung und Ablösung von der Antike in diesem Punkte werden.

Aber die geht nicht von den Männern aus, deren Weltgefühl von der neuen Wissenschaft sich nährt. Der Mechanismus führt zwangsläufig vom Individuellen $a b-$ und nur krasse Seinsspaltung ermöglicht es Descartes, an der Einzelseele als Substanz neben der homogenen Weltmaterie festzuhalten; eine Ungelöstheit, der sich Spinoza dann, der pantheistischen Tradition willig hingegeben, mit der Konsequenz einer Gesamtheitssubstanz auch für das Seelische entzieht. Dies alles ist Gegnerschaft und polemische Anknüpfungsgelegenheit für Leibniz, nicht Vorbereitung und innerer Einfluss.

Es ist das Zeitalter ber Gotik, als das der wirklichen Loslösung von der antiken Form und des ersten Aufbaues ganz aus eigenem Vermögen, in dem auch diese Begriffswandlung sich durchringt. Mit der Erhebung des Individuellen zu Form und Idee legt Duns die erste Bresche in die scholastische Festung. Von da hört der Kampf für das Einzelne und dessen bezeichnendste und höchste Ausprägung in der individuellen Person nicht auf; der vielbesprochene Individualismus der Renaissance bedeutet nur einen Abschnitt in dieser grossen Bewegung. Im Durchsetzen des Einzelnen - nicht als logische Theorie und in der Tendenz, die der Name bezeichnet - hat der aufkommende Nominalismus seine eigentliche zeitgeschichtliche Bedeutung. Zugleich arbeitet, jedoch in der eigentümlichsten Verquickung mit ihrer pantheistischen Neigung, die deutsche Mystik für das neue Ziel. Die bedeutsamste begriffliche Erfüllung vor Leibniz erzwingt, mitten im Kampfo noch, Nikolaus von Kues. - 
Dass der individualistische Gedanke einer von jenen wenigen grossen Motiven war, die vom ersten Selbstbesinnen an Leibniz' Bildungen bedingen, unabhängig von den jeweils für ihn verfügbaren Lösungsbegriffen und Zeitgegebenheiten, das haben noch jüngst entwicklungsgeschichtliche Betrachtungen bestätigt (Kabitz). Individualistische Gestaltung schon der allgemein-ontologischen Grundlagen, unbedingte Abwehr jeder Art von pantheistischer Durchkreuzung, und dies in der ganz bestimmten Richtung auf die Umbildung des fundamentalen Seinsbegriffs nach dem Vorbild der Einzelseele: das bestimmt, vor allen Fragen von Materie und bewegender Kraft, von zusammengesetztem und einfachem Sein, Leibniz' Forderung nach einer nenen Definition der Substanz. Die wirklichen Ursprünge des Monadengedankens liegen hier allein.

Grundsätzlich steht für Leibniz dieses fest: dass unmittelbar, in Selbstgegebenheit das Sein nur durch reflexive Selbstschau zu fassen ist, und dass allein in solcher Erkenntnisstellung wie alle ersten ontologischen Kategorien so auch das Wesen der Substanz primär sich ergibt. Da sie selbst als Substanz sich weiss, kann die Seele erkennen, was überhaupt Substanz charakterisiert. Nun macht vor allem andern die Reflexion dieses klar: dass in der Konsequenz der Substanzdefinition nicht die Einzelseele zum Teile oder Modus umfassenderen Seins werden darf. Da sie vielmehr, trotz offensichtlich mangelnder Aseität, trotz Abhängigkeit von Gott in Schöpfung und Erhaltung, ihm nach der inneren Aussage gegenübersteht in Selbstheit, Selbstentscheidung, Selbstverantwortung als Person zu Person, so muss der Substanzbegriff auf beide, Seele wie Gott, anwendbar sein; auch Kreatur ist „Selbstand“. Keinen ärgeren Feind für den wahren Weltbegriff weiss sich Leibniz (ausser nur dem Materialismus) als die „Monopsychiten“, deren Weltseele die andern "einschluckt". So gibt das seelische Einzelwesen den Urtypus der Substanz ab. Was es zum Einzelnen macht, ist nicht Negation ursprünglicher Universalität, herabziehende Materie, sondern formhafte Position des einzig wirklichen Seins: "substantielle Form" in neuem Sinne.

Des Weiteren definiert Substanz sich als ursprüngliche Aktivität; Selbstand ist Selbstehen, Selbsttun, Handeln aus eigenem Vermögen. Auch darin erkennt man den Atem der neuen Zeit, der in Seele und Welt alles Sein und Leben zu Entwicklung und Tätigkeit wird. Mit Duns begann die Abwendung von den pas- 
sivistisch statischen Zügen im scholastischen Intellektualismus; von ihm an reift stetig der Ausdruck für das Dynamische der Seele auch in der Mystik, der Gegenwendung im letzten Gotteserlebnis zum Trotz. "Selbstentfaltung“, Selbstentwickeln der inneren Keime, lebendige Tätigkeit stellt sich entgegen aller Geringschätzung tätigen Daseins, dem Einfliessen und der Bestimmung von aussen, der willenlosen Preisgabe an Gegebenes. Daseinskreise sind Kreise des Auswirkens, des Selbstentfaltens. Und alles Entfalten zielt auf Selbststeigerung, ist Streben nach der eigenen Erfüllung, nach „Vollkommenheit“. In langem Ringen siegt ein selbst- und daseinsfreudiges Ethos über selbstverlorene weltabgewandte Kontemplation. Nicht nur die Seele, alle "Kreatur" gewinnt ein neues Leben.

Das sind die Ursprünge von Leibniz' Begriff der Kraft-Substanz. Das Sein der Seele ist Tun, ihr „Zustand“ ein „Zustand der Veränderung“. „Das Zeugnis innerer Erfahrung und unseres Bewusstseins“ zeigt unmittelbar, dass „bei uns etwas Selbsttätiges vorhanden ist"; und das religiös-ethische Selbstgefühl sagt weiter aus, dass darin der Kern unseres Daseins ist. Jede Seele ist "eine Kraft, eine von der Macht Gottes verschiedene Wirksamkeit ${ }^{u}$; was wäre sonst Sünde. Also gehört Aktion wesenhaft zur Substanz. Die „inneren Handlungen der Seele“ sind der Beweis für die ${ }_{n}$ Absurdität der Lehre, die den endlichen Substanzen die Aktion absprechen" will. Liegt es in der Natur der geschaffenen Substanz, sich stetig zu verändern, ist alle Ruhe nur scheinbar, nur unmerkliche Veranderung, gehemmter Akt, so ist dies nirgends unmittelbarer zu verstehen, als an der Seele, die nur im Akte ist. Nicht ruhendes Substrat für ein Oberflächenspiel von Bewegungen und Wechsel, für das Kommen oder Gehen, Abnehmen. und Abgeben von Attributen ist die Substanz, sondern das Prinzip der Selbsttätigkeit und Veränderung, das innere Leben ist im Kern selbst des beharrenden Wesens. Operari sequitur esse; actiones sunt suppositorum; aber nicht in dem Sinne, als ob das Sein auch obne operari wäre, die supposita aktionslos sich denken liessen. Die im innersten Wesen und nach ihrem letzten Sinn und Wert stetig fliessende bewegte strebende Seele zeigt solche Ursprungseinheit in Selbstgegebenheit. Alles was handelt ist Einzelsubstanz; und jede Einzelsubstanz handelt ohne Unterbrechung. Das Selbstbewusstsein der Seele wiederlegt schlagend den Occasionalismus und bewahrt auch hier vor der pantheistischen Konse- 
quenz. Nur als selbsthandelndes Prinzip, als Entelechie kann das Einzelwesen wirklich Substanz beissen.

Und wie in der Seele das Urbild der Substanz, so fassen wir in ihrem dynamischen Akt, in Begehren und Streben, das Prinzip aller und jeder wahrhaften Veränderung, des Werdens überhaupt. Ja der Ursprung der Zeitordnung selbst ist darin gegeben. Gerade von der Seelenherkunft des Substanzgedankens aus entsteht die Gegenforderung zu jener religiös-idealistischen Verweisung des Zeitlichen zum metaphysisch Unwichtigen und Unwirklichen. Zwar hält auch hier die Lehre vom „kompletten Begriff“ die Prävalenz des überzeitlich ideellen Sinngehalts aufrecht - als die folgerichtige Ausbildung der mit dem neuen Individualismus seit Duns Scotus der bis dahin allein herrschenden Allgemeinidee zum Trotz durchgesetzten Idee des Individuellen. Auch wird der Akt selbst ursprünglich zeitlos gefasst. Aber die religiös-ethischen Aufgaben der Entfaltung und Vervollkommnung fordern Zeitrealität, ein metaphysisch reales Auseinanderlegen aller in der Individualidee zum punktuell zeitlosen Akt zusammengezogenen Stadien des inneren Lebens. Die Antinomik, die bei Eckehart und Nikolaus in aller mystischen Vergottung sich erhält, bleibt auch bei Leibniz ungelöst bestehen. -

Jede Art von mechanistisch verstandenem Wirken ist damit a limine abgewiesen: da dort Alles Gestossenwerden ist, ein Zentrum stets nur Kreuzungspunkt und Durchgang, nje Ursprung und selbsttätiges Anheben. Nicht im Stoss und seiner Kausalität zeigt sich die substantielle Kraft. Aber auch nach den scholastrschen Begriffsfassungen bedarf es stets noch der Auslösung, des Anreizes von aussen, der Gelegenheitsursache, um Geschehn an der Substanz hervorzurufen. Wie wäre aber mit dem Selbstwert und der reinen Innerlichkeit der Person solche Abhängigkeit vom Äusseren verträglich. Von innen muss alles kommen, nicht nur die Fähigkeit und Spannung, sondern ebenso Auslösung und Wirkensbeginn. Spontaneität, aus sich beginnende und selbst dem eigenen Wirken Halt und Grenze setzende Kraft - nicht Kansalität, gleichviel in welcher Form, ist die dem wahren Substanzbegriff zuzuordnende Kategorie. Substantielles Wirken entspringt und verbleibt in der Innerlichkeit der Substanz, die reines Beisichselbstsein ist. So erst kommt es zu vollkommener Selbstheit, Einzelheit, zu geschlossener Individualität, in deren Eigensein Geschick und Zukunft ganz sich erfüllt. 
So findet das grosse neue Lebensgefühl der Selbsttätigkeit und Selbstbestimmung in Leibniz' Substanzbegriff die extreme Konsequenz. "Wir sind nur dem Anscheine nach dem Zwange unterworfen und befinden uns, streng metaphysisch genommen, in einer vollkommenen Unabhängigkeit von dem Einflusse aller Geschöpfe ". Auch die unendliche Substanz wirkt nur insoweit auf die Seele, als diese samt ihrer Selbsttätigkeit ihr Dasein und Erhaltung verdankt; in den Gang ihrer Entfaltung und Entscheidung aber greift auch Gott nicht ein. Kein äusserer Einfluss gilt; was auch der Seele, der Substanz zustösst, es kommt aus ihrem Inneren, entspringt dem eigenen Vermögen und ist durch die eigene Natur „vollkommen geregelt und gegen alle $\mathrm{Zu}$ fälle von aussen sichergestellt" - „durch eine vollkommene Selbstbestimmung". Erleiden ist nicht Folge äusserer Kraft, sondern Ausdruck für die Begrenztheit der inneren. Mit solcher Konsequenz erst ist für Leibniz die ,immer gleichförmige Erhaltung unserer Individualität", als Grundlage für die Unsterblichkeit der individuellen Seele, garantiert.

Jede Einzelsubstanz ist ein Sein für sich, das, unabhängig von allem Äusseren, Umgebenden, sich selbst genügt. Das Vorbild vollkommenen Beisichselbstseins in religiöser Innerlichkeit bestimmt den Seinsbegriff. Was immer für das Einzelwesen Sein und Bedeutung haben mag, es muss in ihm selbst zu finden, dem eigenen Sein eingeordnet sein. Die fremde Aussenwelt fällt weg. Dass aber die Isolierung nicht Verarmung bedeutet, dafür tritt jetzt der ontische Zusammenhang mit Gott ein! Durch seine Vermittlung zieht der Reichtum der Welt, aus deren kosmischer Verflochtenheit die Person sich losgelöst, in diese sich hinein. Eine innere Welt baut sich auf, nicht aus dem blossen Stoff von Sünde und Heil, wie in asketisch gestimmter Seelen- und Weltlehre, sondern in der ganzen verschwenderischen Fülle und mit allen Zügen der einstigen Aussenwelt. An die Stelle des realen Zusammenhangs, 'der das Einzelne in sich aufzulösen droht, tritt ideelle Verbundenbeit durch Entsprechung: so wird Universalität in das einzig reale Individualsein selbst hineingenommen. Die Einzelseele wird fähig, das gesamte Dasein, die unendliche Welt selbst in sich zu fassen, sich ins Unendliche zu weiten. Jene Unendlichkeits-Vermittlung verbürgt ihr das. In den Spuren des unendlichen Gottes besitzt sie die ganze unendliche Welt. Nichts ist ihr grundsätzlich verschlossen von allem was ist, in ihrer unendlichen Selbstentwick- 
lung hat sie nur zu entfalten, was sie dem Wesen nach besitzt. „Jede Seele kennt das Unendliche, kennt alles . . . doch verworren." Auf die Gegebenheitsform, den Vorstellungsgrad kommt es für den Seinsbegriff nicht an; das Wesentliche ist, dass so im Gottesursprung das isolierte Selbst den Weltzusammenhang wieder gewinnt. Der Gedanke vom Mikrokosmus, bei den deutschen Denkern vor Leibniz so innig vertieft, kommt hier zu einer äussersten Erfüllung. Jede Seele ist „wie eine Welt für sich, sich selbst genügend, unabhängig von jeder anderen Kreatur, schliesst das Unendliche in sich und ist, indem sie das Universum ausdrückt, ebenso dauerhaft, fortbeständig und absolut wie das Universum der Kreaturen selbst". So wird, doch ohne solipsistische Verödung, in letzter Steigerung des Individualismus das Einzelne zum Einzigen. Zugleich aber, doch ohne Preisgabe der Person im Allverfliessen, das Selbst zur Welt. -

Dass nur das Einzelding Substanz ist, ist ontologische Notwendigkeit und gilt für jedes mögliche Dasein. Gott wie Seele als Person, Selbsttätigkeit - das steht fest vor allen Fragen der Welteinrichtung und der Werteordnung. Doch die Erfüllung des Einzelwesens mit der Totalität des Seienden durch die vollkommene Entsprechung des Inneren mit allem Äusseren: das zeigt die Spuren des höchsten Sinnes; der Grundsatz des Besten waltet da. Zwischen Gott und Seele besteht realer Zusammenhang der einzige, den es gibt: in der einzig wirklichen Kausalität von Schöpfer (Erhalter) und Kreatur. Auch das ist metaphysische Notwendigkeit. So könnte jede Seele für sich und ohne alle Umwelt sein, gleichviel in welchen Inhalten sie leben würde. Aber das Sinnsystem des göttlichen Willens lässt solche Vereinzelung und Verzettelung nicht zu; es errichtet auf dem Grunde des realen Zusammenhanges einen alles umfassenden ideellen, der jedes Einzelwesen mit dem ganzen übrigen Dasein vereint, ohne doch ihm seine Selbstgenugsamkeit und Unabhängigkeit zu rauben. In den unendlich verflochtenen Beziehungen des Sinnsystems hat jedes Einzelne und jeder Zug in ihm seine Stelle; damit liegt schon im Einzeldasein mit "moralischer" Notwendigkeit der innigste Bezug auf alles andere. Und da ist nichts zuerst oder zuletzt; es giebt kein Wesen, das nur Mittel wäre; ein jedes ist Selbstzweck, Selbstand - und Rücksicht, Beziehung auf alles Andere zugleich. Und diesen Sinnbezug nimmt es mit in die zeitliche Existenz, und bringt ihn darin zur Entfaltung. Als Gottesschöpfung ist 
jede Kreatur Weltspiegelung. Durch die Gottesverbundenheit wächst jedem Wesen die Teilhabe an allem anderen Dasein, die „Sympathie" mit allem Existierenden zu. "Prästabilierte Harmonie“ ist zwischen allem was in der Einzelseele vor sich geht und dem was „ausser" ihr, d. h. im Inneren aller anderen Kreaturen geschieht. Indem die Seele nur aus dem "eigenen Schatze", dem eigenen „eingeborenen “ Wesen ihre Inhalte, die „inneren Phänomene“ sukzessiv nach dem „ihr eingepflanzten Gesetz“ entfaltet, repräsentiert sie, in vollkommener und unfehlbarer Entsprechung, den gesamten Weltlauf. In der reinen Innerlichkeit ist die Gesamtheit alles Äusseren enthalten; nicht selbstgegeben, nicht durch Realeinwirkung übertragen, sondern durch die Vermittlung eines höchsten Ordnungsgesetzes nach seinem geistigen Gehalt repräsentiert. -

Auf solchem metaphysischen Grunde und Zusammenhang (dessen geschichtlicher Bezug zur deutschen Mystik und Theosophie ohne Weiteres erhellt - ein Blick auf Nikolaus von Kues zeigt alle Mittelsfäden) erwächst auch Leibniz' Erkenntnislebre deren Prinzipien zur Illustration noch eben angedeutet seien. (Ausführlicheres und Belege in meiner Schrift über Leibniz' Methode der Erkenntnis, Kap. Erkenntnislehre und Monadologie).

Der Weg, den Descartes für die philosophische Fundierung aller Erkenntnis und Wissenschaft forderte: Rückwendung zum existenzgewissen Ich und seinem Ideengehalt, Erweiterung und Aufstieg zur unendlichen Substanz, Übergang endlich durch deren Vermittlung auf Aussenwelt und äussere Erfahrung - dieser hier nur zum Zwecke einer einmaligen Grundlegung zu beschreitende und auf solche „methodische“ Bedeutung beschränkte Umweg bezeichnet in Leibniz' metaphysischer Erkenntnislehre den unumgänglichen Verlauf eines jeden auf Aussenwelt und Dinge gerichteten Aktes. Da nach ihm grundsätzlich kein Berühren von Ich und Dingen, kein Hinüberwandern und Einfliessen des Äusseren ins Innere statthat, das Einzelwesen vielmehr unbedingt in seiner reinen Innerlichkeit verbleibt, so kann es keine Brücke von Sinneseindrücken und Willenseinfluss geben zwischen Seele und Aussenwelt. Nicht aus kausalen Vermittlungen, wo dann nur noch deren Wahrheitsgehalt durch Gott zu garantieren ist, konstitniert sich der Zusammenhang von Seele und Welt, sondern in der Gottesherkunft und im Gottesbezug allein ergreift die nach innen gewandte Seele das Universum der Dinge. Und dies nicht, 
wie im Occasionalismus, durch eine mit jedem Akt einspringende Wunderkausalität Gottes, sondern durch die ideelle Vermittlung der Repräsentation.

Es ist nicht so, wie es nach den üblichen Darstellungen scheinen muss, als ob für Leibniz das Erkennen eine Sonderart des Repräsentierens wäre, oder gar im Grunde, als „Vorstellen“, damit zusammenfiele. Vorstellung und Repräsentation der Monade entstammen ganz verschiedenen Zusammenhängen: jene dem Übergewicht des Seelisch-Subjektiven über alles Materielle und Dingliche in Leibniz' Seinserlebnis, diese der Ausgleichslösung für die Ansprüche von Einzelwesen und Weltsystem. -- Die Monadenlehre kennt auch sowohl Repräsentieren ohne Vorstellung und Erkennen, als Erkenntnisse, in denen kein Repräsentieren mitspielt.

Erkennen als solches ist auch für Leibniz ein seelisches Erfass en von unmittelbar Gegebenem. Die einzige Haltung aber, in der solches Ergreifen möglich ist, ist die nach innen gewandte Reflexion, die Selbstschau der Seele. Das innere Objekt ist das einzig unmittelbare Objekt. Einzig in der Selbstschau des Ich kommt die Erkenntnis zum Sein. Die „Sonne“ und "alles was ist, sehen wir in uns selbst und in unserer Seele".

Es muss nur der Begriff des Ich weit genug gefasst werden. Was wir innerlich erfassen, ist nicht nur die eigene Person, die Seelensubstanz, das Ich und seine Akte, sondern ebenso die "Ideen" dieser Akte: die identischen Gehalte ihres wechselnden Auftretens, Farben und Zahlen, Anschauungen und Begriffe, Konkretes und Abstraktes, Zeitlichkeits- and Ewigkeitsinhalte. Diese Ideen im Ich, die „inneren Phänomene" vor allem, werden bezeichnet als "das unmittelbare innere Objekt", sind das direkte Gegenüber des Subjekts, das es erfasst, durchleuchtet, "begreift".

Während aber beim Erfassen des Ich und seiner Akte die Erkenntnisbedeutung des inveren Objekts in diesem selbst aufgeht, ist der Intentionsgehalt der inneren "Ideen" nicht der eigentliche Gegenstand ihrer Akte. Ob sie intelligibel oder sinnlich sind, Stoffe der "ewigen Wahrheiten" oder der Erfahrungssätze, sie beziehen sich auf Äusseres. Hier tritt die Repräsentation ein, als eindeutige Zuordnung jeder inneren Gegebenheit - soweit sie nicht, wie beim Ich und seinen Akten Selbstgegebenheit von Existierendem ist - zu äusserem Sein und Dasein, des inneren Wechsels zu äusserem Geschehen. 
Diese ideelle Entsprechung aber wird ermöglicht und wird garantiert durch den Realzusammenhang der Seele mit Gott als ihrem Schöpfer. Die in sich selbst vertiefte Seele erfasst sich als Gotteskreatur und ist damit auf Gott selbst bezogen. „Vermöge jener Kenntnis von der Seele kennen wir das Sein, die Substanz und Gott selbst". Gott ist das „einzige unmittelbare äussere Objekt" des Erkennens, weil hier allein das Innere mit dem Äusseren in realem Zusammenhang, dem der Schöpfung und Erhaltung, steht. Der Ausdruck ist leicht misszuverstehen: als ob hier nun doch einmal das Äussere selbst in sich vom Ich gefasst würde, als ob Erkenntnis hier real hinausgriffe aus dem Ichbereich. So ist es nicht: auch hier ist schon Repräsentation und insofern "mittelbares" Objekt. Die Kreatur ergreift nicht (wie die Mystik wollte) die unendliche Substanz selbst, in sich, sondern nur deren Projektion auf die eigene beschränkte Ebene; Gottes Bild fasst sie in dem Spiegel ihres Inneren. Dass aber der Spiegel den Abglanz von äusserer Realität gibt, das beruht eben auf jenem Realzusammenhang (dem einzigen den es gibt) und wird in ihm erlebt. Und darin allein besteht die Unmittelbarkeit in dieser Beziehung der Erkenntnis auf ein äusseres Objekt.

Alle sonstige Erkenntnis von Äusserem ist dagegen nur mittelbar, Erfassen von Inhalten, die in keiner direkten Realbeziehung zu den eigentlichen Erkenntnisobjekten stehen, sondern ihnen nur zufolge der prästabilierten Harmonie, d. h. des gemeinsamen Ursprungs aller Dinge im teleologischen System, eindeutig zugeordnet sind. Die Seele kann den Spiegel der Natur in sich fassen, weil sie ein Spiegel Gottes ist; wie die Welt nur als der vollkommenste Ausdruck Gottes, als Realisierung des Prinzips des Besten besteht, so wird sie auch nur als solche und nur zufolge dieser Funktion erkannt - in der Reflexion auf das eigene gottentstammte Ich. Als den uns mitgegebenen Lebensreichtum fassen wir die Welt, nicht als das, was unserer Einsamkeit gegenüber steht und uns beschränkte. Auch hier bleibt der Ton auf der Dualität und dem Personcharakter der letzten Grundlagen von Erkennen und Sein; die Formulierung des Zeitgenossen Malebranche, dass wir alles in Gott sehen, wird um des pantheistischen Zuges willen abgelehnt. Der Blick der Seele bleibt in ihr selbst beschlossen, auch da wo sie zum Erfassen Gottes und durch ihn hindurch zur Kenntnis der Welt vordringt.

Alles was die Seele erkennt ist ihr "eingeboren". Nicht nur 
das Rational-Apriorische, sondern ebenso alles Sinnlich-Empirische. Das war es auch, worauf die Entwicklung in der Erkenntnislehro von Duns Scotus und Eckehart über Nikolaus und Valentin Weigel hinauslief. (Auch hier ist keineswegs Descartes der "unmittelbare Vorgänger" von Leibniz!) Der „Schatz“ der Seele umfasst mit dem Gottesbild alles Weiltensein, Umwelt, Vergangenheit, Zukunft jedweden Lebens. Nichts was je ist und sein kann ist mir fremd, mir äusserlich; alles kann ich in mir finden, wenn ich suche. Trennungen durch Raum und Zeit sind ohne letztgiltige Bedeutung. Die Möglichkeiten des Erkennens sind ohne Grenzen.

Alle Forschung und Erarbeitung von Erkenntnis aber besteht in der Klärung und Sichtung des inneren Besitzes, im Auseinanderlegen und gesonderten Begreifen des konzentriert Gegebenen. Die Sinnstruktur in den zunächst nur verworren und dunkel empfundenen Massen der „inneren Phänomene“ deutlich zu verfolgen, die Gründe herauszuschälen aus allem, was als bloss Faktisches sich gibt, die Gründe, die schliesslich alle in dem Prinzip des Besten sich vereinen - das ist der eigentliche Wert und Sinn aller Wissenschaft vom Wirklichen.

Und möglich wird diese eben durch die zwiefache Gegebenheit in uns: des Gottesabdrucks in der Seele, und des damit vererbten göttlichen Weltbildes. Mit dem Ersten hält das erkennende Subjekt die intelligiblen Ideen („Attribute Gottes“), repräsentierend die ewigen Ideen in Gottes Verstand und den einzigen Vollkommenheitsbeschluss in Gottes Willen; den Stoff der „ewigen Wahrheiten", die das Apriorisch-Deduktive für alle Wissenschaft liefern. Die zweite Gegebenheit aber ist die „äussere" Erfahrung in jeder Art und Form, das Aposteriori, die für ein endliches Wesen (das nie bis zum vollkommenen Durschschauen des ganzen Zusammenhanges und zur reinen Deduktion des Universums vom Apriori her gelangt) unumgängliche Grundlage aller Existenzaussagen. Mit den Mitteln der ersten Gegebenheit und Erkenntnis wird es möglich, die Analyse der zweiten, die sonst in der Unendlichkeit von lauter Einzelheiten stecken bleiben müsste, in grossen Zügen durchzuführen, und in dem Aufbau der Naturgesetze und der empirischen Prinzipien die Herkunft vom teleologischen Apriori für weite Strecken zu erkennen. - 
Vom Personerlebnis aus ist Leibniz' Metaphysik fundamental als Pluralismus bestimmt. Doch ist die Vielheit der Seelen nicht bloss numerische Menge, bloss quantitative Unendlichkeit der Weltwiederholung. Jedes einzelne ist ein Einziges nach Wesen und Wert; einzig nicht nur in der inneren Geschlossenheit, sondern obenso in der Art seiner Repräsentation des Ganzen. Gott denkt denselben Gedanken nicht zweimal; auf besondere Art trägt jede Seele seine Spur, auf besondere Weise stellt sie die Welt dar. Im universalen Bezug verliert sich nicht, erfüllt sich vielmehr erst der individuellste Wert. Jede einzige Seele bedeutet die Realisation einer einzigen Weltperspektive. Die Weltansichten aller Seelen sind "sämtlich verschieden und sämtlich wahr". "Indem Gott sozusagen von allen Seiten und auf alle Weise das allgemeine System der Phänomene dreht, das zu produzieren ihm gefiel um seinen Ruhm offenbar zu machen, und indem er so alle Seiten der Welt auf alle möglichen Weisen betrachtet . . . entsteht als Resultat jedes Blicks auf das Universum . . . eine Substanz, die das Universum ausdrückt, dieser Ansicht gemäss . .." So wird die Welt, die schon an sich die Spuren Gottes in der aktuellen Unendlichkeit ihrer inneren Struktur trägt, in jeder Seele noch einmal geschaffen, gespiegelt in einzigartiger Beleuchtung; sie wird in unendlichen Seelen unendlich vervielfältigt. „In jeder Seele könnte man die Schönheit des Universums erkennen, wenn man alle ihre Falten auseinander legte"; aber gerade dass sie so in "Falten" zusammengezogen ist, in jeder Seele auf eigene Art, das steigert die unendliche Fülle unendlichmal. Es ist der alte Gedanke der individualistischen Mystik, der hier von Gott auf die Welt, als Gottesausdruck, übertragen - und von dieser dann auf ihn zurückgeleitet wird.

Gott und die Seelen - das ist für die christliche Metaphysik der Grundbestand des Seins, wesenhafter und gewisser als sonst irgend etwas. Und die Frage ist immer, was ausser diesem etwa noch die "Welt" bedeuten kann. Im mittelalterlichen Denken und noch bei Descartes sind die unsterblichen Seelen Wertinseln in einem Ozean vergänglicher Materie, mübsam sich behauptend und durchsetzend gegen die feindliche Flut; alles aussermenschliche Dasein ist da an sich indifferent und ohne Selbstwert, als Mittel hie und da zu achten, zu verwerten; doch meist als das die reine Ord- 
nung Verwirrende und vom Wert Abziehende zu bekämpfen. Die glühende Daseinsliebe und Naturverehrung des neuen Weltgefühles kann dabei nicht bleiben. Ihr Losungswort ist überall die Überwindung von Fremdheit und Feindschaft zwischen Seele und Welt, Mensch und Natur. So sieht des Franz von Assisi selige Liebe nur Brüder und Schwestern um sich in dem sonst tot und seelenlos geglaubten Dasein. Und so bereitet im Norden, den neuen Weisungen des Meister Eckehart nachspürend, Seuse und weiter Paracelsus den Boden für ein lebendiges Fühlen und Fassen alles Lebendigen. Nicht auf dem Boden von Descartes' Weltspaltung in Seele und Materie-Maschinen steht Leibniz' Weltgedanke, sondern auf dem der deutschen Naturphilosophie, mit ihrem Vitalismus und Psychismus. Wer „die Tiere zu reinen Maschinen erniedrigt“, hat nicht die rechte Vorstellung "von der Majestät der Natur", als der Gotteswelt, in der es „nichts Unbewohntes, nichts Unfruchtbares, nichts Totes" geben kann.

Die schon im scholastischen und Cartesianischen Dualismus offengebliebene Frage fand zu Leibniz' Zeit die beiden radikalen Entscheidungen: nur Materie gibt es, und auch die Seelen sind Maschinen, und: nur Seelen, „Geister" sind, und alles Materielle, Aussermenschliche ist deren Traum und Vorstellung. Beides unmöglich für Leibniz: der Materialismus ist sinnwidrig schlechthin und schlägt aller sichersten Gewissheit ins Gesicht; aber auch Berkeleys Ausweg gilt ihm als "absurd“; das ist Herabwürdigung der Naturmajestät, ist Missachtung der Gotteskreatur, deren Selbstwert da zu Vorstellungsspiel und Seelennahrung verflüchtigt wird.

Die Träume der in sich beschlossenen Seelen sind $n$ gut fundiert" - d. h. nicht etwa nur, dass sie "gut geregelt" sind und einander entsprechen, dass sie mit ibren Sonderperspektiven auf ein und dasselbe Weltbild, auf ein zentrales Phänomensystem bezogen sind. Sondern wie ich mit den Vorstellungen, die ich von Menschen um mich habe in meinem inneren Erleben, reale Seelen treffe, so bezeichnen alle die Bilder von den Tieren und den Pflanzen in meinen „inneren Phänomenen“ reale Substanzen, mit allen den Grundattributen derselben, Einzelwesen nach der Art der Seelen. Alles Lebendige ist seelenähnlich, ist wie beseelt, soweit man nur den Begriff des Seelischen nicht unbillig auf das Menschlich-Geistige beschränkt. Und das setzt sich fort bis in die kleinsten Teileinheiten der organischen Wesen; überall sind 
wieder Lebenseinheiten, zur höheren Gesamteinheit des Tiers, der Pflanze ideell gruppiert.

Und das Tote, das Unorganische, die Materie? Das scheint nur tot und materiell, ist in Wahrheit ein Gewimmel von unendlich vielen Einzelwesen, die alle lebendig, alle seelenăhnlich sind. Was immer ist und in der Vorstellung gespiegelt wird, es ist substantielles Einzelwesen, individuell, immateriell, in reiner Innerlichkeit sich entfaltend, selbsttätig und durchaus selbstbestimmt, unabhängig vom äusseren Zufall. „Es würde weder der Ordnung noch der Schönheit noch der Vernunftgemässheit der Dinge entsprechen, wenn das Lebendige oder innerlich Tätige nur in einem kleinen Teile des Stoffes enthalten wäre. . ." Die Welt des Stosses und der Kausalität ist nicht, als nur in der verworrenen, das Kleine übersehenden und zur Masse vermengenden Vorstellung. Kein Ding ist in sich je „im Zustand der Untätigkeit und Nutzlosigkeit". Die höchste Achtung, die Kants Sittengesetz für jedes Menschendasein fordert: "niemals bloss Mittel", wird hier dem geringsten Wesen und dem kleinsten Ausschnitt der Natur entgegengebracht. Aus "Lebensprinzipien" (den Abkommen der Archeen des Paracelsus) und in deren ideeller Gruppierung, gegliedert nach der jedem einzigen zugeteilten Aufgabe der Gottes-Welt-Repräsentation, setzt alles Dasein sich zusammen. Was sich als homogen gibt, als Kontinuum, gleichförmig Wiederholtes, Fliessendes, alle Räumlichkeit und Ausdehnung, Masse und Bewegung - das zeigt damit allein schon, dass es nicht wahrhaft ist. Die Majestät der Natur duldet nichts indifferent Gleichförmiges und Undeterniniertes; nur Individuen sind da, die der eigenen und einzigen Entwicklung innerlich nachgehen. Der Satz Spinozas vom Negationscharakter aller Determination wird auf den Kopf gestellt: das Nicht-Determinierte, Nicht-Vereinzelte ist Negation des wahren Seins. Nicht Verschiedenheit und bunte Vielspältigkeit ist das Zeichen des Scheines, wie im antiken Denken und bei allen denen, die davon sich nähren; sondern gerade Gleichheit und Gleichförmigkeit, Ununterscheidbarkeit.

Die Versöhnung von Seele und Welt war die neue Aufgabe, da beide zu lieben sind als Gotteswerk und Ausdruck göttlicher Vollkommenheit. Der Pantheismus gab, indem er die Seele eintauchte in die vergöttlichte Welt, das Ursprungszentrum, den Ausgangswert auf: die Person. Leibniz geht den andern Weg: Annäherung alles Daseins an das Seelensubjekt, Einführung der 
Prinzipien der Individualität, selbsttätigen Innerlichkeit, Selbstbestimmung in die Welt und alles Wirkliche, Zusammenschluss der unendlichmal unendlichvielen realen Einzelwesen in einem ideellen System, das jedem seine einzigartige Stelle und seine unvergleichliche Aufgabe verbürgt.

Das so entstehende grandiose Weltbild mit allen seinen weiten Perspektiven und Konsequenzen, wie auch mit dem Fragwürdigen und Ungelösten darin, kann hier nicht mehr beschrieben werden. Alles was den Gedanken von Gottesruhm, Unendlichkeitsrepräsentation und Weltfülle im Seelenbegriff anfrichtete, wird nun nochmal unendlich potenziert. Die grossen Intentionen des Nikolaus von Kues (den Zimmermann mit Recht als den eigentlichen Vorläufer Leibniz' charakterisiert hat) finden hier eine ungeahnte Erfüllung. -

Nur Eines sei noch erwähnt, nicht so sehr um der Vollständigkeit, als um der indirekten Bestätigung willen, die wir darin für den angedeuteten Weltanschauungsursprung der ganzen Monadenlehre zu sehen glauben: die von Leibniz geplante und als erreicht angesprochene Versöhnung von Monaden-Metaphysik und mechanistischer Naturwissenschaft. Bis dahin scheint das System geschlossen und ohne unüberwindliche Schwierigkeit wenn man das eine vielbemerkte Rätsel ausnimmt, das mit der Ausdehnung des Monadengedankens von der Seele auf alle Inhalte des Universums entsteht: was heisst es, dass jede Monade die Welt repräsentiert; die doch allein nur aus Monaden mit der gleichen Funktion besteht . . . was könnte ein gegenseitiges Repräsentieren und Entsprechen von Wesen bedeuten, die nichts anderes sind und haben, als Repräsentation? - Aber überall da, wo die Verbindung mit dem Mechanismus einsetzt, springen die Risse auf, ergibt sich Unmögliches, entstehen Unbegreiflichkeiten, für die noch keine Interpretation das Lösungswort gefunden bat. Das zeigt mit aller Deutlichkeit, dass dieser Versöhnungszusammenhang, der Sachordnung nach, für den Systemgedanken Leibnizens hinterher kam, und sicherlich in keiner Form den Ausgang bildete.

Dass und weshalb es ein Lieblingsgedanke war für Leibniz: im rein Materiell-Mechanischen die teleologischen und immateriellen Gründe aufzuweisen, und dies mit den Mitteln der Wissenschaftslogik selbst, wurde erwähnt. Und zu dem polemischen Motiv der 
Confessio Naturae kam für ihn noch dies hinzu: dass er, bei aller metaphysischen Gegnerschaft zum Mechanismus, sich dennoch so wenig wie irgend ein wissenschaftlicher Kopf des Zeitalters dem ungeheuren Eindruck entziehen konnte, den derselbe als wissenschaftliche Methode machen musste. So galt es denn Brücken zu schlagen von der Welt des Raumes und der Masse, der Kausalität des Stosses und der Bewegung zu seiner Welt des UnräumlichInneren und bloss Sinnverbundenen der immateriellen Einheiten, der Spontanität rein qualitativer, sich selbst treibender und beschränkender Entwicklung.

Zwei Brücken konstruiert Leibniz: die eine von der mechanischen Kausalität, die nur im „Detail“ der Körperwelt statthabe, zum metaphysischem Prinzip hinter allem Einzelgeschehen; in den Bewegungsgesetzen, als den beherrschenden Wissenschaftsprinzipien alles mechanischen Geschehens, waltet nicht mathematisch-phoronomische Notwendigkeit, sondern teleologische "Ökonomie", Konvenienz. - Die andere vom Ausgedehnt-Zusammengesetzten zum Einfachen, vom äusserlich Bewegten zur inneren Tendenz und Entwicklungskraft. Wo Ausdehnung ist, ist wesenhaft auch Teilbarkeit ins Unendliche. Innerhalb der Ausdehnung kommt es nicht zu den Elementen, den einfachen Komponenten des $\mathrm{Zu}-$ sammengesetzt-Teilbaren. Also muss Zusammensetzung, Ausdehnung aus unräumlichen Einheiten "resultieren“. So ist denn die Ergänzung des Mechanismus in der Metaphysik zu suchen! -

Der Übergang könnte leicht und klar scheinen, und doch wird da mit einem Schlage alles ungewiss und wirr. Wie können unräumliche Elemente das "Aggregat" des Räumlichen „zusammensetzen", und wie ist jenes "Resultieren" zu verstehen? Wie wird die innere Kraft zur äusseren, im Raume wirkenden, ja womöglich das Räumliche erst erzeugenden? - Auf welchem Wege kann das Monadensubjekt sich zum realbewegten Körper verdichten, die innere Begrenztheit sich in Bewegungsbeharrung und körperlichem Widerstande äusseren? So viele Übergänge Leibniz zu bilden sucht in seinen Begriffsscheidungen von erster und zweiter Materie, von primitiver und derivativer Kraft - es wird nicht klar, wie der Zusammenhang gemeint sein soll; und keine Deutung hat bis hente den metaphysischen Sinn einheitlich fassen können. Solange die Körperwelt und die Monadenwelt parallel gedacht sind, als das Phänomen, das uneigentliche und verwischende Bild gegenüber dem wahrhaften Sein, kann ein Zusammenhang eben im Sinne 
der Repräsentation noch aufrecht erhalten werden: der Raum symbolisiert in unvollkommener Weise die intelligible Ordnung; Bewogungen symbolisieren Tätigkeiten; Körper - Zuordnungen und teleologische Komplexe von Monaden; Widerstand und Elastizität die innere Abgeschlossenheit und das Selbsthandeln; Kontinuität des Nebeneinander und der Wirkungen - die Formenerfülltheit und Systemverbundenheit der intelligiblen Welt; "Ökonomie" in den Bewegungsgesetzen - die Ökonomie in der Weltspiegelung der Monaden, u. s. f. Auch da allerdings würde die Durchführung im Einzelnen unübersteigliche Schwierigkeiten bieten.

Aber sowie das eine aus dem anderen hervorgehen, die Welt des Mechanismus durch die Fundierung in Monaden auch real sein soll, das Phänomen nicht blosser Schein und wirre Darstellung, sondern eigene, obzwar bloss abgeleitete und unselbstständige, Realität - bricht alles auseinander, was vorher in so einheitlicher Geschlossenheit sich gab. Charakter und Begriff des Phänomens "wechselt von einer Darstellung zur anderen (Näheres und Genaueres in meiner schon zitierten Leibniz-Schrift); die Naturphilosophie und Prinzipienlehre eines aus der mechanistischen Wissenschaft erwachsenen dynamistischen Realismus ringt in den wechselndsten Formen und in der mannigfaltigsten Betonung um den Ausgleich mit dem Idealismus der ursprünglichen Monadenlehre - deren Herkunft wir anzudeuten suchten. Und es scheint, als ob an diesem Punkte ein gigantisches Bemühen scheiterte, das zu vereinen, was unvereinbar war und blieb. - 